BBA 66722

\title{
EXTRACTABILITY OF LYSOZYME FROM BOVINE NASAL CARTILAGE
}

NINO SORGENTEa, VINCENT C. HASCALLb AND KLAUS E. KUETTNERa

aRush-Presbyterian-St. Luke's Medical Center, Department of Orthopaedic Surgery, Chicago, Ill. 60612 (U.S.A.) and ${ }^{\mathrm{b}}$ The University of Michigan, Department of Oral Biology, Ann Arbor, Mich. (U.S.A.)

(Received April 6th, 1972)

SUMMARY

Lysozyme (mucopeptide $N$-acetylmuramylhydrolase, EC 3.2.I.I7) is present in the extracellular matrix of bovine nasal cartilage at a concentration of about 0.03 to $0.08 \mathrm{mg}$ per $\mathrm{g}$ wet tissue $(3-8 \mathrm{mg} /$ Ioo $\mathrm{ml}$ per $\mathrm{g})$. It is extracted from the tissue in guanidinium chloride solutions between 0.3 and $0.8 \mathrm{M}$. These concentrations are much lower than those which effectively extract most of the proteoglycans from the tissue, 2.5-3.0 M. Lysozyme migrates to the top of $\mathrm{CsCl}$ density gradients which are used to purify aggregated or monomer proteoglycan preparations; this suggests that lysozyme is not involved in the aggregation of proteoglycans in vitro. Chondroitinase from Proteus vulgaris effectively removes chondroitin sulfate from cartilage slices without solubilizing lysozyme which indicates that this highly anionic polysaccharide does not immobilize lysozyme in the matrix. Trypsin (EC 3.4.4.4) releases most of the chondroitin sulfate as well as $75 \%$ of the lysozyme from the matrix.

INTRODUCTION

In his classical investigations of lysozyne (mucopeptide $N$-acetylmuramylhydrolase, EC 3.2.I.I7), Fleming observed that cartilage is a particularly rich source for this enzyme ${ }^{1}$. It has since been shown that lysozyme resides in the extracellular matrix in these tissues ${ }^{\mathbf{2}, \mathbf{3}}$. Nevertheless, there is no known substrate in cartilage which lysozyme can enzymatically degrade.

Previous work indicates that the proteoglycans in hyaline cartilages interact with specific proteins or glycoproteins to form aggregated structures ${ }^{4,5}$. Because lysozyme is a strongly cationic protein, and is known to form dissociable complexes with proteoglycan in vitro ${ }^{6}$, it seemed possible that lysozyme might interact with the highly anionic proteoglycans in vivo and that such postulated interactions would be essential to the structure of the tissue.

Bovine nasal cartilage was chosen as a model system to study the relationships, if any, between lysozyme and proteoglycan in the organization of the tissue matrix.

Abbreviation: MES, $N$-(morpholino)ethanesulfonic acid. 


\section{Materials}

Guanidinium chloride (ultrapure grade) and $\mathrm{CsCl}$ (optical grade) were obtained from Mann Biochemicals; $N$-(morpholino)ethanesulfonic acid (MES), from Calbiochem; chondroitinase ABC (chondroitin sulfate, A,B,C,-lyase) from Proteus vulgaris, and Micrococcus luteus (lysodeikticus) cells from Miles Laboratories; egg white lysozyme, salt free, twice recrystallized, and TRTPCK trypsin (EC 3.4.4.4), a preparation in which chymotrypsin is inactivated, from Worthington Laboratories; and special Agar-Noble from Difco Laboratories.

Slices were prepared from fresh bovine nasal cartilage as described previously 4 and used directly in the experiments.

\section{ANALYTICAL METHODS}

Glucuronic acid was determined by the modification of Bitter and Muir of the carbazole procedure of Dische ${ }^{8}$. Densities were measured utilizing a $500-\mu l$ pipette as a pycnometer.

Lysozyme activity was determined by an agar diffusion method ${ }^{\mathbf{9}, 10}$ using hen egg white lysozyme as a standard. The effect of guanidinium chloride on the assay was determined since this salt was used in several experiments. It was found that increasing the concentration of guanidinium chloride in lysozyme samples increased the radii of the observed zones of lysis, Fig. I. In experiments in which guanidinium chloride was used, then, all samples and standards were brought to identical salt concentrations, usually I.5 M. The presence of monomeric proteoglycan, isolated as described previously ${ }^{5}$, at concentrations between $0 . \mathrm{I}$ and $5 \mathrm{mg} / \mathrm{ml}$ did not affect the lysozyme assay. The enzymatic activity in all experiments is expressed as egg white lysozyme equivalents.

Unless otherwise stated, all guanidinium chloride solutions were buffered at $\mathrm{pH}$ 6 with 0.02 M MES.

\section{Extraction of lysozyme from cartilage slices by different concentrations of guanidinium} chloride

I $g$ samples of fresh bovine nasal cartilage slices were extracted for $24 \mathrm{~h}$ at room temperature with Io-ml aliquots which ranged from 0.15 to $\mathrm{I} .5 \mathrm{M}$ in guanidinium chloride. Extracts were separated from extracted slices by filtration through glass wool. The extracts were each adjusted to I.5 M guanidinium chloride by dilution I : I with complementary guanidinium chloride solutions. Glucuronic acid contents and the lysozyme activities were determined.

The extracted cartilage slices from each sample were washed for $\mathrm{I}_{5} \mathrm{~min}$ with a $5-\mathrm{ml}$ aliquot of the same guanidinium chloride solution used for extraction. The washes were discarded. All samples were then extracted for $24 \mathrm{~h}$ with $10 \mathrm{ml}$ of $3 \mathrm{M}$ guanidinium chloride. These extracts were diluted to $1.5 \mathrm{M}$ guanidinium chloride and glucuronic acid contents and lysozyme activities were measured.

Kinetics of release of lysozyme from bovine nasal cartilage

I-g samples of fresh cartilage slices were extracted at $4{ }^{\circ} \mathrm{C}$ with Io vol. of either 
$0.25 \mathrm{M}, 0.50 \mathrm{M}$, or $0.75 \mathrm{M}$ guanidinium chloride. At times between $30 \mathrm{~min}$ and $30 \mathrm{~h}$, $0.5-\mathrm{ml}$ aliquots of each extract were removed and brought to $\mathrm{I} .5 \mathrm{M}$ in guanidinium chloride. Glucuronic acid contents and lysozyme activities were determined.

Release of glucuronic acid and lysozyme from cartilage with chondroitinase $A B C$ from Proteus vulgaris and with trypsin

The commercial chondroitinase $\mathrm{ABC}$ preparations contain small, variable amounts of lysozyme. This lysozyme was separated from chondroitinase activity by chromatography on CM Sephadex $\mathrm{C}_{-50}$. The enzyme ( 5 units/0.5 ml) was applied to a I-ml column of the resin which had been equilibrated in $0 . \mathrm{I}$ M sodium acetate, $0 . \mathrm{I}$ $\mathrm{M}$ Tris, $\mathrm{pH} 7 \cdot 3$. Most of the chondroitinase activity, determined as described elsewhere $^{11}$, was eluted with four $2-\mathrm{ml}$ aliquots of the same buffer whereas $0.4 \mathrm{M} \mathrm{KCl}$ was required to elute the lysozyme activity.

Approximately I unit of activity ${ }^{12}$ of this lysozyme-free chondroitinase in $\mathbf{1} .5$ $\mathrm{ml}$ of the sodium acetate-Tris buffer was used to treat $5^{\circ} \mathrm{mg}$ of cartilage slices at $30{ }^{\circ} \mathrm{C}$. A control cartilage sample was incubated in buffer without enzyme. At times from $\mathrm{I}-8 \mathrm{~h}, \mathrm{o} . \mathrm{I}-\mathrm{ml}$ aliquots were removed from the incubations. After $8 \mathrm{~h}$, the solutions were decanted and the residual slices extracted for $20 \mathrm{~h}$ with $\mathrm{I} .5 \mathrm{ml}$ of $3 \mathrm{M}$ guanidinium chloride. Glucuronic acid contents and lysozyme activities were determined after all the samples were adjusted to I.5 M guanidinium chloride.

In a similar experiment, I50 $\mathrm{mg}$ cartilage slices were incubated at $30{ }^{\circ} \mathrm{C}$ in $\mathrm{I} .5$ $\mathrm{ml}$ of $0.05 \mathrm{M}$ Tris, $0 . \mathrm{I} 2 \mathrm{M} \mathrm{CaCl}_{2}, \mathrm{pH} 8.5$, with or without $0.15 \mathrm{mg}$ TRTPCK trypsin*. The release of glucuronic acid and lysozyme was determined at various times.

\section{Migration of lysozyme in $\mathrm{Cs} C l$ density gradients}

Cartilage slices were extracted with $4 \mathrm{M}$ guanidinium chloride, $15 \mathrm{ml} / \mathrm{g}$ of tissue, for $24 \mathrm{~h}$ at room temperature and the extract isolated by filtration. One-half was dialyzed $24 \mathrm{~h}$ against $7 \mathrm{vol}$. of $0.02 \mathrm{M} \mathrm{MES}, \mathrm{pH} 6.0$. $\mathrm{CsCl}$ was added to the retentate to give an initial density of $1.55 \mathrm{~g} / \mathrm{ml}(0.95 \mathrm{~g} \mathrm{CsCl} / \mathrm{g}$ retentate). A density gradient was established by centrifugation in a SW $50 . \mathrm{I}$ rotor at $40000 \mathrm{rev} . / \mathrm{min}$ at I $8{ }^{\circ} \mathrm{C}$ for $48 \mathrm{~h}$. This gradient is essentially the same as that used to prepare aggregated proteoglycan, referred to as proteoglycan complex ${ }^{13}$. However, a lower initial density was utilized. The gradient was sliced into ten approximately equal fractions with a Beckman tube slicer. Densities, glucuronic acid contents, and lysozyme activities were determined.

$\mathrm{CsCl}$ was added directly to the remainder of the undialyzed cartilage extract to give an initial density of $\mathrm{I} .49 \mathrm{~g} / \mathrm{ml}$. Density gradients were established for I2, 24, 48 and $60 \mathrm{~h}$ by centrifugation in a SW $50 . \mathrm{I}$ rotor at $40000 \mathrm{rev} . / \mathrm{min}$, at $\mathrm{I} 8^{\circ} \mathrm{C}$. The $48-\mathrm{h}$ gradient is the same as that described for the preparation of the monomeric proteoglycan, referred to as proteoglycan subunit ${ }^{5,13}$. At each time point the gradients were sliced into ten approximately equal fractions. Densities, glucuronic acid contents, and lysozyme activities were determined.

* Commercially available, twice recrystallized, trypsin contains small amounts of lysozyme. However, the TRTPCK trypsin used in this experiment was free of bysozyme. 


\section{Effect of guanidinium chloride on agar diffusion assay for lysozyme activity}

In the agar diffusion procedure, with standard conditions, the observed radii of the zones of lysis are proportional to the logarithm of the lysozyme concentration ${ }^{\mathbf{1 0}}$. Fig. I indicates that guanidinium chloride greatly enhances the apparent lysozyme activity up to about I.5 M. The salt apparently facilitates diffusion of lysozyme into the agar. Since standard curves prepared from different concentrations of lysozyme in I.5 M guanidinium chloride are linear but displaced toward larger zones of lysis than those in saline, this salt can be used to increase the sensitivity of the diffusion assay 5-Io-fold. However, the results indicate that the assay will probably be sensitive to variations in the types and amounts of salt in the samples and care must be taken to standardize the analyses.

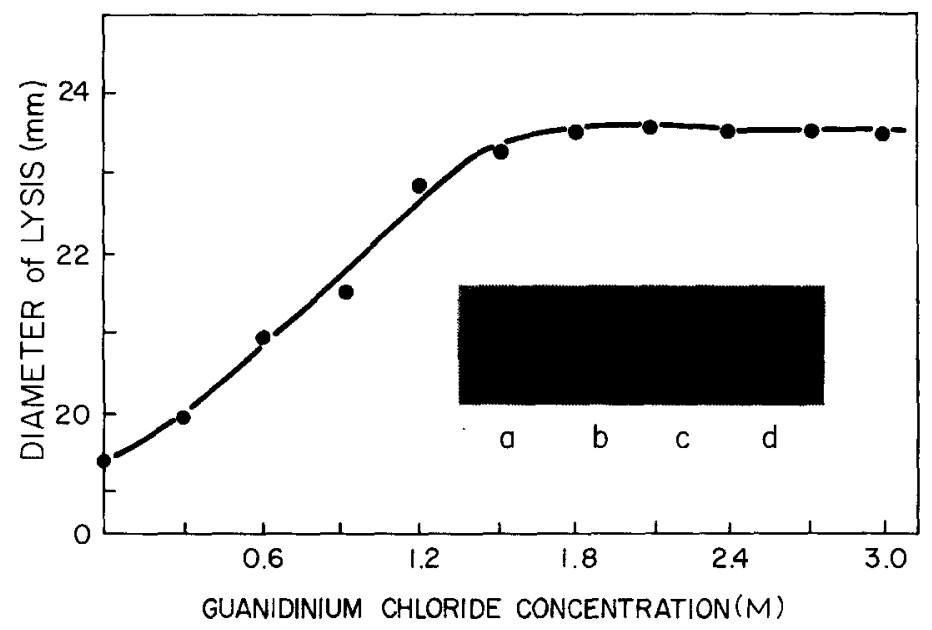

Fig. I. Effect of guanidinium chloride on lysozyme assay. The graph indicates the diameters of lysis observed when aliquots of $5 \mathrm{mg} / \mathrm{r}$ oo $\mathrm{ml}$ solutions of lysozyme in different guanidinium chloride concentrations were applied to the agar. The insert is a photograph of the zones of lysis by lysozyme in (a) saline, and in (b) $1.0 \mathrm{M}$, (c) $\mathrm{I} .4 \mathrm{M}$ and (d) $2.0 \mathrm{M}$ guanidinium chloride.

\section{Extraction of lysozyme from bovine nasal cartilage with different guanidinium chloride concentrations}

Fig. 2 shows the amounts of glucuronic acid, and hence proteoglycan ${ }^{4,5}$, and of lysozyme extracted from cartilage slices by the guanidinium chloride solutions. The additional amounts of glucuronic acid and lysozyme that were subsequently extracted from the slices with $3 \mathrm{M}$ guanidinium chloride are also shown. The total glucuronic acid extracted from each cartilage sample was between 85 and $90 \%$ of the total in the original tissue.

The amounts of proteoglycan recovered in the extracts increased gradually as the ionic strength of the solutions increased. In contrast, lysozyme showed an abrupt increase in extractability at about $0.5 \mathrm{M}$ guanidinium chloride. The amounts of lysozyme found in the subsequent $3 \mathrm{M}$ guanidinium chloride extracts show an inverse relationship. 


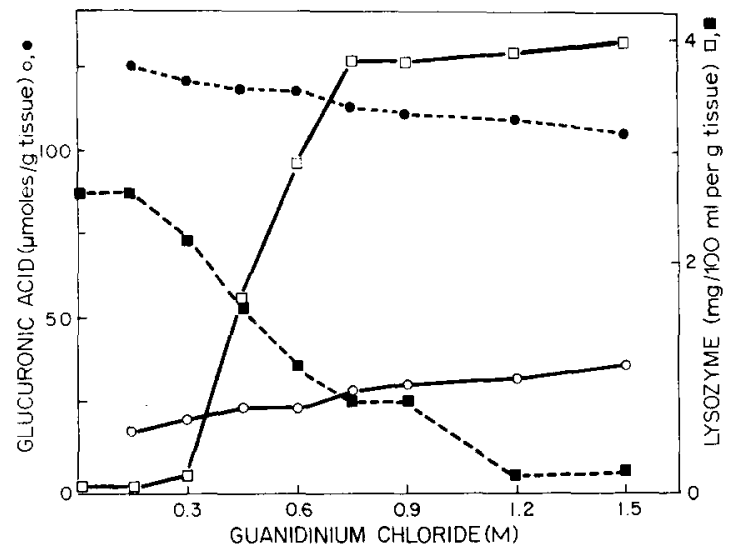

Fig. 2. Effect of guanidinium chloride concentration on the extraction of glucuronic acid $(\mathrm{O}-\mathrm{O})$ and lysozyme $(\square-\square)$ from cartilage slices. The additional amount of glucuronic acid (0---0) and lysozyme ( cated.

The lysozyme activity is released from the tissue at a considerably lower ionic strength than that required to release most of the proteoglycans, $2.5 \mathrm{M}-3.0 \mathrm{M}$ guanidinium chloride 4 . Further, at low (below $0.3 \mathrm{M}$ ) guanidinium chloride concentrations, IO-I5\% of the proteoglycan, but none of the lysozyme is released from the tissue. These results suggest that the binding of lysozyme within the cartilage matrix may be independent of the proteoglycan pool that is extractable with $3 \mathrm{M}$ guanidinium chloride.

\section{Kinetics of the release of lysozyme from cartilage tissue}

Fig. 3 shows the amounts of glucuronic acid and of lysozyme which are extracted from cartilage slices with time in three guanidinium chloride concentrations at $4{ }^{\circ} \mathrm{C}$. Glucuronic acid is released gradually in all three solutions, although the higher ionic strengths are a little more effective. Only about $15 \%$ of the total glucuronic acid in the tissue is extracted after $30 \mathrm{~h}$ in the $0.75 \mathrm{M}$ solution. The release of lysozyme is significantly different. The $0.25 \mathrm{M}$ solution extracted no lysozyme; the $0.50 \mathrm{M}$ solution released about $50 \%$ of the tissue lysozyme within 5 -Io $\mathrm{h}$ and then a plateau was reached; and the $0.75 \mathrm{M}$ solution released essentially all the lysozyme activity in the tissue within Io $\mathrm{h}$. These results indicate that the total amount of lysozyme which can be extracted depends upon the guanidinium chloride concentration and that the kinetics of release of lysozyme and of proteoglycan differ.

Release of glucuronic acid and lysozyme from cartilage treated with chondroitinase $A B C$ or with trypsin

The major anionic component of the proteoglycans in nasal cartilage is chondroitin sulfate, which can be digested with bacterial chondroitinases. A chondroitinase was used to remove this polysaccharide from cartilage slices to see if such treatment would enhance the release of lysozyme from the tissue. Two chondroitinases have been partially purified and characterized, chondroitinase AC from Flavobacterium heparinum and chondroitinase $\mathrm{ABC}$ from $P$. vulgaris ${ }^{12}$. In preliminary experiments, 

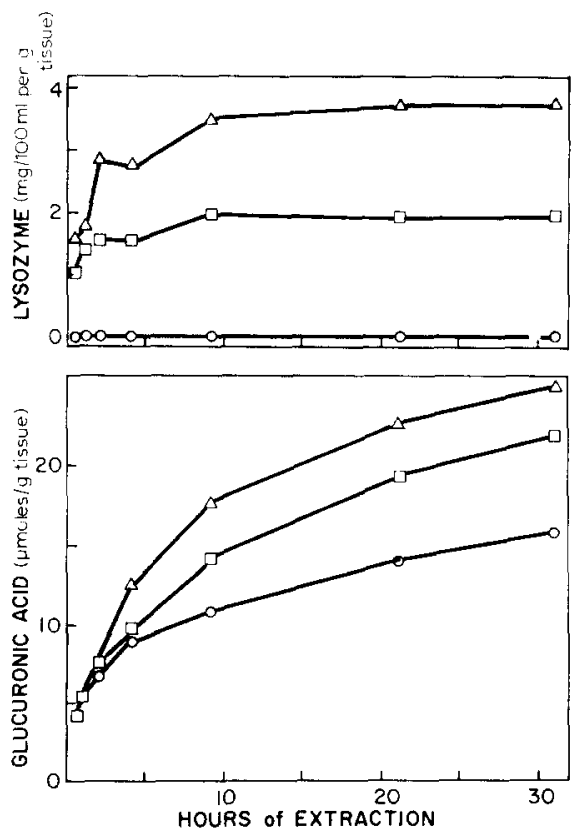

Fig. 3. Effect of time on the amount of glucuronic acid and lysozyme extractable in $0.25 \mathrm{M}$ $(O-O), 0.5 \mathrm{M}(\square-\square)$ and $0.75 \mathrm{M}(\Delta-\triangle)$ guanidinium chloride.

we found that the commercially available preparations of both enzymes contain lysozyme activity. The amount of lysozyme in the chondroitinase $\mathrm{ABC}$ samples was small, however, and this enzyme was used after the lysozyme was removed.

Fig. 4 compares the release of glucuronic acid and lysozyme in the presence or absence of the enzyme over an 8 -h incubation time at room temperature. About $65 \%$ of the glucuronic acid in the tissue was released by the enzyme, whereas less than $15 \%$ was released in the control. No lysozyme activity was released in either sample until the slices were subsequently extracted with $3 \mathrm{M}$ guanidinium chloride. In similar experiments in which the samples were incubated at $37{ }^{\circ} \mathrm{C}$ up to $85 \%$ of the uronic acid in the tissue was released by the chondroitinase without releasing lysozyme. These data suggest that the lysozyme molecules are not bound directly to chondroitin sulfate in the tissue matrix and that this polysaccharide is not acting as an ionic barrier for the release of the lysozyme.

Fig. 5 shows the release of glucuronic acid and lysozyme in the presence or absence of trypsin. In the presence of this enzyme, $75 \%$ of the glucuronic acid is released in $20 \mathrm{~min}$ and the amount increases to $90 \%$ after $2 \mathrm{~h}$. In controls, only about $15 \%$ of the glucuronic acid was released. In the presence of trypsin, $75 \%$ of the lysozyme was released into the medium after $40 \mathrm{~min}$ and this amount remained constant throughout the remaining incubation time. The additional $25 \%$ could be extracted from the slices with $3 \mathrm{M}$ guanidinium chloride. In the controls, lysozyme was only recovered in the subsequent $3 \mathrm{M}$ guanidinium chloride extract.

Trypsin is a highly selective protease which does not degrade egg white lysozyme $^{14}$ or native collagen ${ }^{15}$. The experiment indicates that bovine nasal cartilage lysozyme is also resistant to digestion with trypsin. Most of the cartilage lysozyme is 

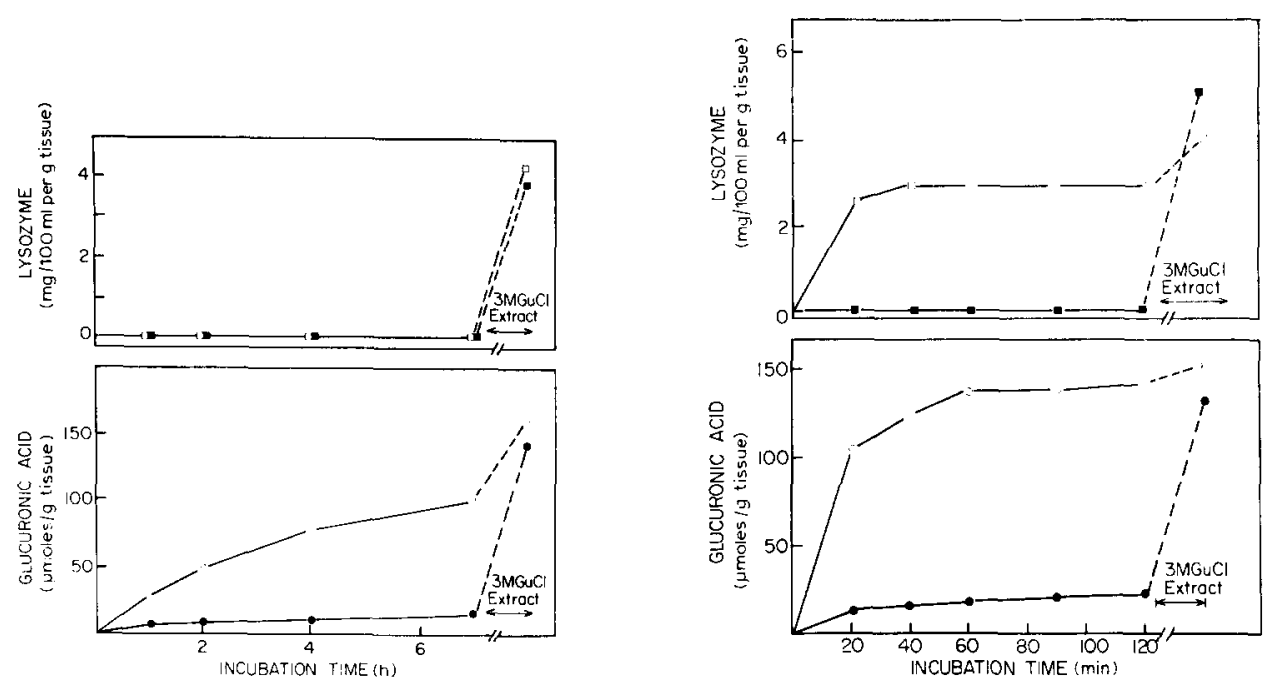

Fig. 4. Release of glucuronic acid (O-O) and lysozyme ( $\square-\square$ ) from cartilage slices treated with chondroitinase ABC from Proteus vulgaris. The closed symbols indicate the release of glucuronic acid and lysozyme from slices in the absence of chondroitinase. The dotted lines indicate the additional glucuronic acid and lysozyme released when the slices were subsequently extracted with $3 \mathrm{M}$ guanidinium chloride $(\mathrm{GuCl})$.

Fig. 5. Release of glucuronic acid $(\mathrm{O}-\mathrm{O})$ and lysozyme $(\square-\square)$ from cartilage slices treated with trypsin. The closed symbols indicate the release of glucuronic acid and lysozyme from slices in the absence of trypsin. The dotted lines indicate the additional glucuronic acid and lysozyme released when the slices were subsequently extracted with $3 \mathrm{M}$ guanidinium chloride $(\mathrm{GuCl})$.

rapidly released by proteolysis which suggests that the binding sites for these molecules reside in or near proteins which are hydrolyzed. The fact that approx. $25 \%$ of the lysozyme is not released by trypsin suggests that some of the molecules may be bound to sites within the matrix, perhaps on collagen fibrils, which are resistant or inaccessible to the proteolytic activity.

\section{Migration of lysozyme in $\mathrm{CsCl}$ density gradients}

The aggregation of cartilage proteoglycans is mediated by a glycoprotein fraction which migrates to the bottom of a $\mathrm{CsCl}$ density gradient established in the presence of low concentrations of guanidinium chloride; but which migrates to the top of gradients established in high guanidinium chloride concentrations ${ }^{4,5}$. The possibility that lysozyme is one of the factors involved in aggregation was investigated.

Table I shows the distribution of glucuronic acid and lysozyme in the two types of $\mathrm{CsCl}$ density gradients. The first, established in $0.5 \mathrm{M}$ guanidinium chloride, is used to purify aggregated proteoglycan, which is recovered in the bottom two-fifths of the gradient. Lysozyme accumulated at the top of the gradient as is indicated by the enzyme activity recovered in Fractions I-4. This indicates that the lysozyme does not bind to the proteoglycan molecules under conditions where they normally interact with small molecular weight proteins or glycoproteins to form aggregate complexes ${ }^{5,13}$, and suggests that lysozyme is not involved in proteoglycan aggregation in vitro.

The gradient established in $4.0 \mathrm{M}$ guanidinium chloride (Table I) is the same as that described for preparing monomer proteoglycan directly from a cartilage extract ${ }^{5}$. 
TABLE I

MIGRATION OF GLUCURONIC ACID AND LYSOzYME IN $48 \mathrm{~h}$, CsCl DENSITY GRADIENTS IN O.5 M AND 4.O M GUANIDINIUM CHLORIDE

\begin{tabular}{|c|c|c|c|c|c|c|}
\hline \multirow[t]{2}{*}{ Fraction } & \multicolumn{3}{|c|}{$0.5 \mathrm{M}$ guanidinium chloride } & \multicolumn{3}{|c|}{$4.0 M$ guanidinium chloride } \\
\hline & $\begin{array}{l}\text { Density } \\
(g / m l)\end{array}$ & $\begin{array}{l}\text { Glucuronic } \\
\text { acid } \\
(m g / m l)\end{array}$ & $\begin{array}{l}\text { Lysozyme } \\
(\mathrm{mg} / \text { Ioo } \mathrm{ml})\end{array}$ & $\begin{array}{l}\text { Density } \\
(g / m l)\end{array}$ & $\begin{array}{l}\text { Glucuronic } \\
\text { acid } \\
\text { (mg(ml) }\end{array}$ & $\begin{array}{l}\text { Lysozyme } \\
(\mathrm{mg} / \text { Ioo } m \mathrm{l})\end{array}$ \\
\hline I & I. 39 & 0.27 & I 2.0 & I.35 & o. 18 & 8.0 \\
\hline 2 & I. 42 & O. I I & $9 \cdot 4$ & I. 37 & O.I 2 & I.9 \\
\hline 3 & I. 45 & 0.07 & I. 5 & I. $4^{\circ}$ & $0.2 \mathrm{I}$ & 2.9 \\
\hline 4 & I. 47 & 0.07 & 0.8 & I. $4^{2}$ & 0.28 & $3 \cdot 3$ \\
\hline 5 & I. 5 I & O. I I & 0.0 & I. 45 & 0.34 & I.O \\
\hline 6 & I. 54 & o. I4 & 0.0 & 1.48 & 0.85 & 0.6 \\
\hline 7 & I. 58 & 0.16 & 0.0 & I. 52 & 2.23 & 0.0 \\
\hline 8 & I. 62 & 0.22 & 0.0 & I. 55 & 3.49 & 0.0 \\
\hline 9 & I. 67 & 0.34 & 0.0 & 1.60 & 4. I 4 & 0.0 \\
\hline To & I. 73 & I I .20 & 0.0 & I. 68 & 6.87 & 0.0 \\
\hline
\end{tabular}

The migration of lysozyme in this gradient was similar to that observed in the first gradient except that a peak of enzyme activity was observed in Fractions 3 and 4 . For this reason, an experiment was designed to observe the migration of lysozyme in this type of density gradient in more detail. Gradients were established for different lengths of time: $12,24,48$ and $60 \mathrm{~h}$. The distribution of glucuronic acid in the gradients, Fig. 6, indicates where the proteoglycan molecules migrate. By 24 h a boundary of proteoglycan was observed at Fraction 5, which subsequently reached the bottom four fractions by $48 \mathrm{~h}$. At $60 \mathrm{~h}$ the proteoglycans are compressed further toward the bottom. On the other hand, as the lysozyme activity migrates toward the top of the gradient, it showed a peak of activity in the middle of the gradient for the 12,24 , and $48 \mathrm{~h}$ times. By $60 \mathrm{~h}$ almost all the lysozyme was recovered in the top four fractions.

The peak of lysozyme activity at the early times corresponds roughly to the boundary of migration of proteoglycan to the bottom of the gradient. The results

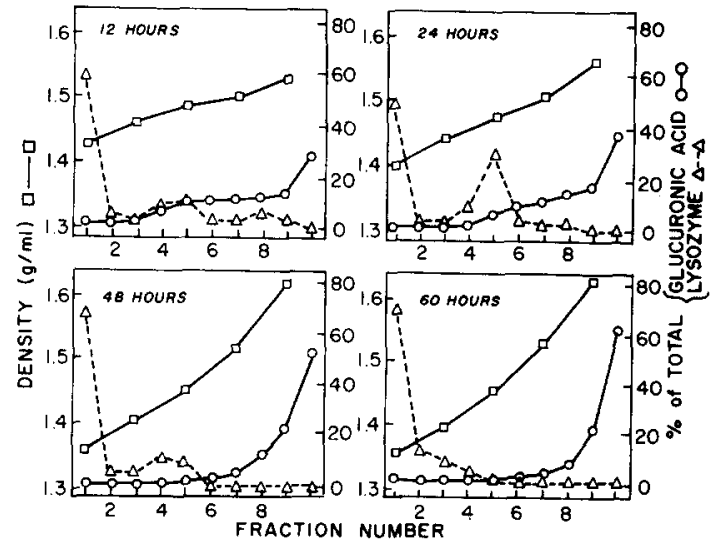

Fig. 6. Distribution of glucuronic acid $(O-O)$ and lysozyme $(\triangle--\triangle)$ in density gradients established in $4 \mathrm{M}$ guanidinium chloride after centrifugation for $12,24,48$ and $60 \mathrm{~h}$ as described in Experimental Procedure. $\square-\square$ indicates the densities of the fractions. 
suggest that the centripetal migration of lysozyme is slowed by the proteoglycans in the bottom part of the gradient. This is reasonable, since these latter molecules contribute significantly to the viscosity of the solution. Once free of the proteoglycan boundary, the lysozyme molecules migrate more rapidly to the top of the gradient. These observations are a demonstration of the type of phenomenon described by Johnston and Ogston ${ }^{\mathbf{1 6}}$. These results suggest that the $4^{0}-4^{8-h}$ gradients described earlier for monomer proteoglycan preparations ${ }^{5}$ were not centrifuged long enough for all the small protein molecules to reach equilibrium positions within the gradient. Thus, the effectiveness of separating such molecules as lysozyme from proteoglycan will depend upon the length of centrifugation and on the proteoglycan concentration.

\section{DISCUSSION}

Lysozyme can associate with proteoglycan to form salt-like compounds that can be dissociated with $0 . \mathrm{I}_{5} \mathrm{M} \mathrm{KCl}^{6}$. The studies described here suggest that cartilage lysozyme, even though highly cationic, is not bound in the tissue through such anionic interactions with the proteoglycans. Nevertheless, it does seem to bind selectively with some components within the extracellular matrix. Extraction of the cartilage lysozyme occurs at lower guanidinium chloride concentrations, $0.8 \mathrm{M}$, than those which cause hen egg white lysozyme to denature, I.9 $\mathrm{M}^{17}$. This suggests that the effect of guanidinium chloride on extraction of lysozyme is a dissociation and not a denaturation process.

The substances which bind lysozyme within the matrix are apparently concentrated primarily within the lacunar area. This is indicated by observations that exogenous lysozyme added to epiphyseal cartilage in culture is primarily bound in the lacuna ${ }^{18-21}$, and that endogenous native lysozyme is also localized within the lacuna ${ }^{2}$.

It has been found that hen egg white lysozyme is capable of binding to neutral sugars and oligosaccharides without hydrolyzing them ${ }^{22}$. The oligosaccharides are bound to the active site of the enzyme in a manner similar to that in which the native substrate of the enzyme is bound. It is possible, then, that the function of lysozyme in the tissue is related to its ability to interact with oligosaccharides built into the structure of the matrix. The binding loci could consist of oligosaccharides, such as have been reported to occur in collagen ${ }^{23,24}$. If true, such an hypothesis might offer an explanation for why the active site of cartilage lysozyme has been preserved through evolution even though no substrates for the enzymatic activity of lysozyme are found in the tissue.

\section{ACKNOWLEDGEMENTS}

We thank Dr D. Dziewiatkowski and Dr R. Eisenstein for advice and support and $\operatorname{Dr} A$. Lindenbaum for his critical review of the manuscript. We wish to thank Mrs P. Lisk, Miss A. Laurick, Mr H. Guenther and particularly Mr C. Reynolds and Mr J. Kaiser for technical assistance.

This work was supported by the National Institutes of Health AM-09I32 and by the National Institute of Dental Research Grant DE-0273I. 


\section{REFERENCES}

I A. Fleming, Proc. R. Soc. London, Ser. B, 93 (1922) 306.

2 K. E. Kuettner, R. Eisenstein, L. W. Soble and C. Arsenis, J. Cell Biol., 49 (I971) 450.

3 C. Arsenis, R. Eisenstein, L. W. Soble and K. E. Kuettner, J. Cell Biol., 49 (I97I) 459.

4 S. W. Sajdera and V. C. Hascall, J. Biol. Chem., 244 (I969) 77.

5 V. C. Hascall and S. W. Sajdera, J. Biol. Chem., 244 (I969) $23^{84}$.

6 M. Schubert and E. C. Franklin, J. Am. Chem. Soc., 83 (I96I) 2920.

7 T. Bitter and H. M. Muir, Anal. Biochem., 4 (I962) 330.

8 Z. Dische, J. Biol. Chem., I67 (1947) 189.

9 K. E. Kuettner, H. I. Guenther, R. D. Ray and G. F. B. Schumacher, Calcified Tissue Res., I (I968) I98.

ro G. F. B. Schumacher, J. Reprod. Med., I (1968) 6I.

I I V. C. Hascall, R. Riolo, J. Hayward and C. C. Reynolds, J. Ccll Biol., 297 (1972) 4521.

I 2 T. Yamagata, H. Saito, O. Habuchi and S. Suzuki, J. Biol. Chem., 243 (I968) I523.

I 3 S. W. Sajdera, V. C. Hascall, J. D. Gregory and D. D. Dziewiatkowski, in E. A. Balazs, Chemistry and Molecular Biology of the Intercellular Matrix, Vol. 2, Academic Press, New York, I970, p. $85 \mathrm{I}$.

I 4 P. Jolles, Angew. Chem. Int. Ed. Engl., 3 (I964) 28.

I5 K. Kuhn, J. Kuhn and K. Z. Monnig, Physiol. Chem., 326 (I96I) 5o.

I6 J. P. Johnston and A. G. Ogston, Trans. Faraday Soc., 42 (1946) 789.

I7 K. Aune and C. Tanford, Biochemistry, 8 (I969) 4579.

I 8 K. E. Kuettner, L. Soble, R. Eisenstein and J. A. Yeager, Calcified Tissue Res., 2 (I968) 93.

I9 K. E. Kuettner, L. W. Soble, H. L. Guenther, R. L. Croxen and R. Eisenstein, Calcified Tissue Res., 5 (1970) 56.

20 R. Eisenstein, C. Arsenis and K. E. Kuettner, J. Cell Biol., 46 (1970) 626.

2 I K. E. Kuettner, L. W. Soble, R. D. Ray and R. L. Croxen, J. Cell Biol., 44 (1970) 329.

22 J. A. Rupley, L. Butler, M. Gerring, R. J. Hartdegen and R. Pecoraro, Proc. Natl. Acad. Sci. U.S., 57 (1967) 1088.

23 L. W. Cunningham, T. D. Ford and J. P. Sagrest, J. Biol. Chem., 242 (Ic67) 2570.

24 R. G. Spiro, J. Biol. Chem., 244 (1969) 602.

Biochim. Biophys. Acta, $284(1972) 44 \mathrm{I}-450$ 